\title{
Aortic valve repair with valve-sparing root replacement for asymmetric quadricuspid aortic valve and conversion into symmetric tricuspid valve
}

Yuki Ikeno, MD, Katsuhiro Yamanaka, MD, PhD, Hiroshi Tanaka, MD, PhD, and Yutaka Okita, MD, PhD, Kobe, Japan

\author{
From the Department of Cardiovascular Surgery, Kobe University Graduate School of Medicine, Kobe, Japan. \\ No funding was provided for the work. \\ Disclosures: Authors have nothing to disclose with regard to commercial support. \\ Received for publication Nov 21, 2018; revisions received Feb 7, 2019; accepted for publication Feb 10, 2019; \\ available ahead of print March 23, 2019. \\ Address for reprints: Yutaka Okita, MD, PhD, Division of Cardiovascular Surgery, Department of Surgery, Kobe \\ University Graduate School of Medicine, 7-5-2 Kusunoki-cho Chuo-ku, Kobe 650-0017, Japan (E-mail: \\ yutakaokita@gmail.com). \\ J Thorac Cardiovasc Surg 2019;158:e25-7 \\ $0022-5223 / \$ 36.00$ \\ Copyright (C) 2019 by The American Association for Thoracic Surgery \\ https://doi.org/10.1016/j.jtcvs.2019.02.035
}

Video clip is available online.

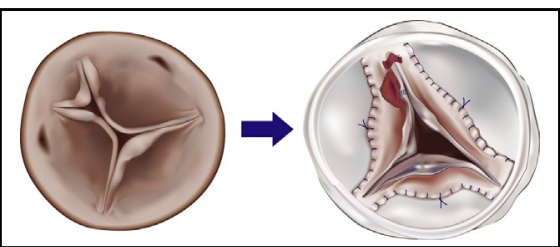

Surgical schema of tricuspidization for asymmetric quadricuspid aortic valve.

Central Message

The surgical outcome of tricuspidization for asymmetric quadricuspid aortic valve with valve-sparing root replacement was satisfactory for a young patient.

See Commentary on page e29.
Quadricuspid aortic valve (QAV) is a rare congenital cardiac anomaly, with a frequency of $0.006 \%$. In a large series, aortic regurgitation (AR) was found in $26 \%$ of the patients with QAV. ${ }^{1}$ Although aortic valve replacement (AVR) is considered to be the standard procedure for QAV, some have reported success with valve repair.

Valve-sparing root replacement (VSRR) is a wellestablished procedure for the treatment of aortic root aneurysms. Several modifications in the surgical techniques and intraoperative monitoring devices have contributed to significant improvement in the long-term outcomes after this procedure. As a result, the indications for VSRR have expanded to include AR secondary to complex aortic cusp pathologies requiring additional cusp repair. We previously reported a successful case of symmetric QAV repair with VSRR. $^{2}$

In this report, we present new insights into asymmetric QAV repair involving (1) the resection of the rudimental commissure, (2) translocation of the cusp deeper into the left ventricular outflow tract, and (3) VSRR for annuloplasty.

\section{CASE}

We present the case of a 58-year-old woman underwent medical screening for chest pain. Transthoracic echocardiography revealed severe AR. Medical therapy was initiated, with no improvement of her symptoms. The left ventricular diastolic diameter had increased to $55 \mathrm{~mm}$, without a decrease in ejection fraction $(78 \%)$. The regurgitation volume was $61 \mathrm{~mL}$, and the regurgitation fraction was $38 \%$. Transesophageal echocardiography identified the aortic valve as a QAV (Figure 1). The diameter of the annuloventricular junction was $22 \mathrm{~mm}$ (index, $12.3 \mathrm{~mm} / \mathrm{m}^{2}$ ), the sinus of Valsalva was $30 \mathrm{~mm}$, and the sinotubular junction was

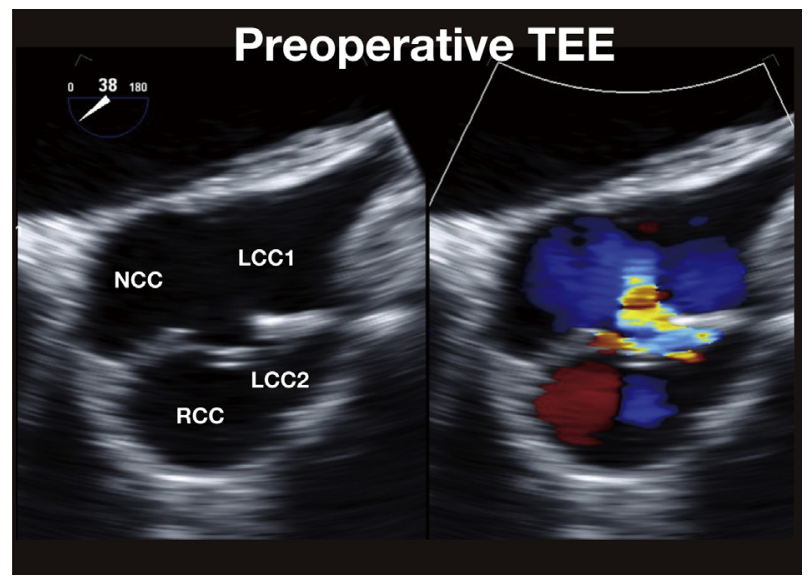

FIGURE 1. Preoperative transesophageal echocardiography (TEE) Aortic valve consisted of 4 leaflets: 2 unequal small cusps and 2 equal large cusps (Hurwitz F type). NCC, Noncoronary cusp; LCC1, left coronary cusp $1 ; L C C 2$, left coronary cusp $2 ; R C C$, right coronary cusp. 

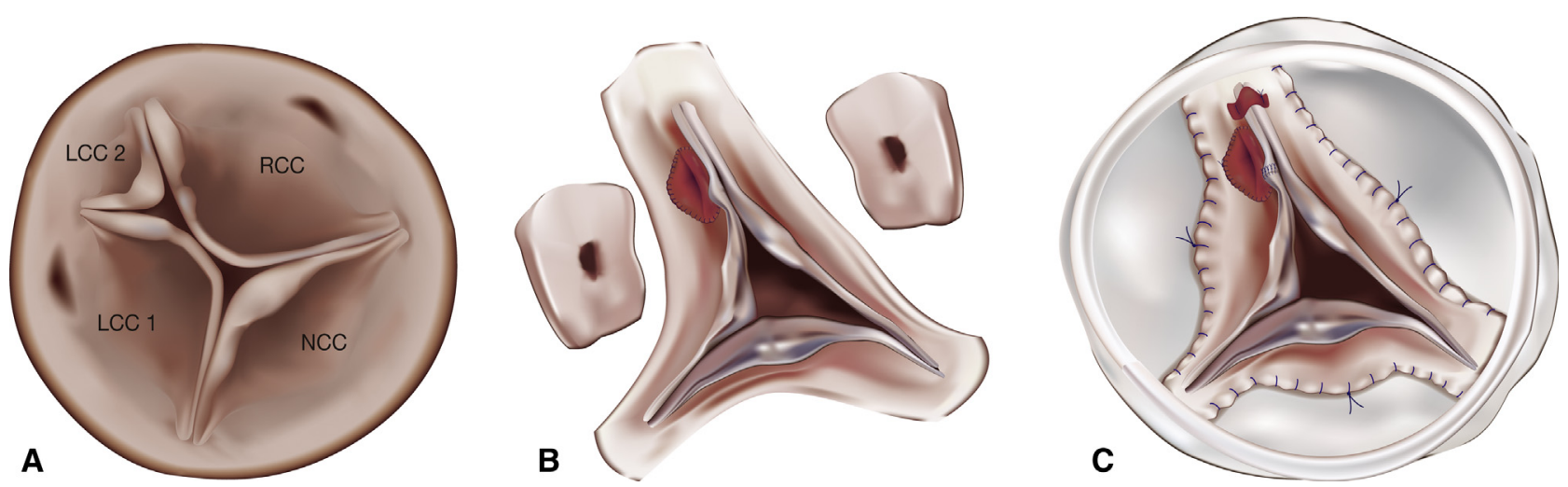

FIGURE 2. Operative schema. A, A rudimentary commissure was found in the left coronary cusp (LCC) that separated it into 2 unequal cusps ( $L C C 1$ and $L C C 2)$. B, The rudimentary commissure was removed, and the leaflet was enlarged with a $0.6 \%$ glutaraldehyde-treated autologous pericardial patch translocated to a position lower in the left ventricular outflow tract. C, Aortic root replacement with a valve-sparing preimplantation technique and tricuspidization with central plication and commissural plication. $R C C$, Right coronary cusp; $N C C$, noncoronary cusp.

$30 \mathrm{~mm}$, and the body surface area was $1.79 \mathrm{~m}^{2}$. The patient was referred to our department for surgical intervention.

\section{OPERATIVE PROCEDURE}

The patient was electively taken to the operating room. Cardiopulmonary bypass was established with ascending aorta and bicaval cannulation. The aortic valve consisted of 4 leaflets: 2 unequal small cusps and 2 equal large cusps, which ware classified as Hurwitz F type. A rudimentary

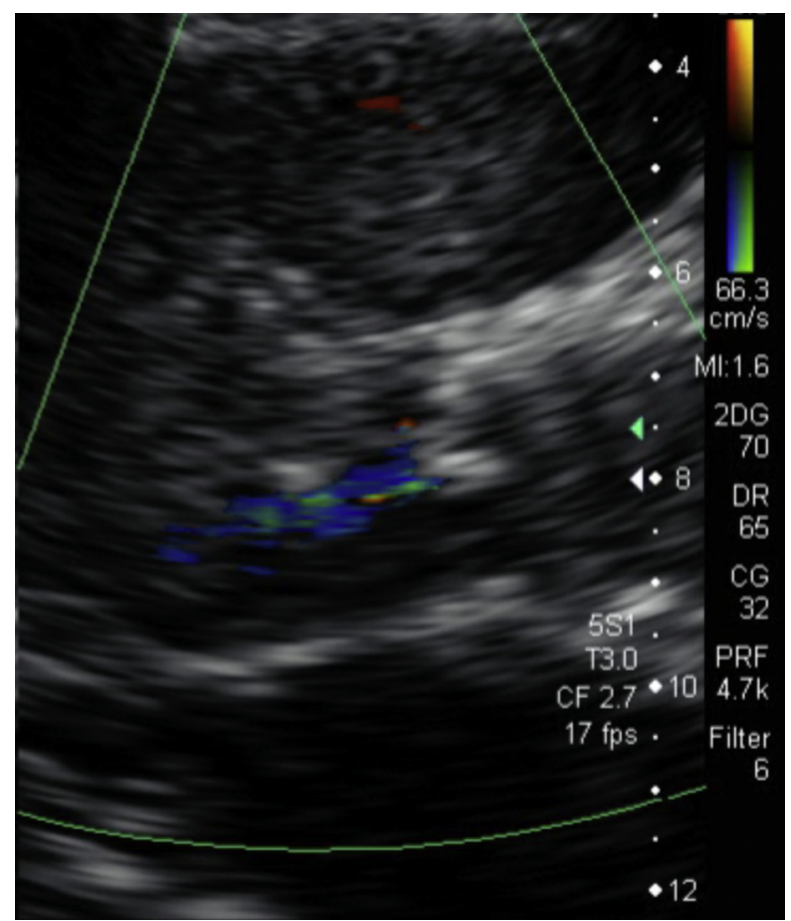

FIGURE 3. Long-axis view of 1-year follow-up transthoracic echocardiography. commissure was found in the left coronary cusp (LCC); this separated the LCC into 2 unequal cusps (LCC1 and LCC2; Figure 2, A). The free margin of the rudimentary commissure was thickened and calcified. Similar changes were found in the commissure between LCC1 and the noncoronary cusp. The geometric heights were $20 \mathrm{~mm}$ in the right coronary cusp, $21 \mathrm{~mm}$ in the noncoronary cusp, $19 \mathrm{~mm}$ in LCC 1 , and $12 \mathrm{~mm}$ in LCC2. To make 3 symmetric cusps, the rudimentary commissure was removed and the leaflet enlarged with a $0.6 \%$ glutaraldehyde-treated autologous pericardial patch. The leaflet was then translocated to a lower position in the left ventricular outflow tract (LCC1 + LCC2; Figure 2, B).

The aortic root was replaced with a 26-mm Valsalva graft (Terumo Medical, Somerset, NJ) and secured with 12 reinforced 3-0 polyester mattress sutures in the first row and continuous 5-0 polypropylene sutures in the second row. After suturing of the second row, central plication of LCC 1 and LCC 2 was added, along with commissural plication of LCC2 and the right coronary cusp with autologous pericardium (Figure 2, C).

Implantation of the coronary arteries and distal anastomoses was completed after confirmation of competency of the aortic valve. Ascending aortic replacement was performed with a 26-mm woven Dacron polyester gelatin implanted graft. Intraoperative transesophageal echocardiography demonstrated no residual AR. The patient's postoperative course was uneventful, and the patient is doing well 1-year postoperatively without recurrence of AR (Figure 3 and Video 1).

\section{DISCUSSION}

The application of VSRR in the treatment of severe AR without aortic root dilation remains controversial. In this report, the reimplantation technique had 2 


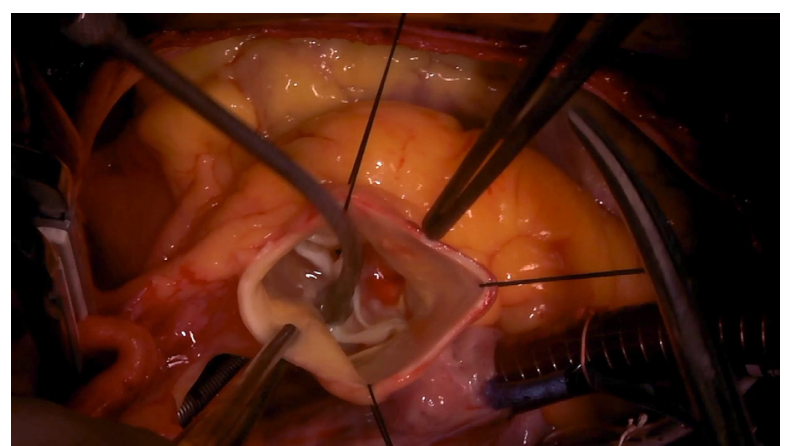

VIDEO 1. Under cardiac arrest, the replacement of the aortic root was performed with a 26-mm Valsalva graft (Terumo Medical, Somerset, NJ) with 12 reinforced 3-0 polyester mattress sutures in the first row and continuous 50 polypropylene sutures in the second row. The rudimentary commissure was detached and enlarged with a $0.6 \%$ glutaraldehyde-treated autologous pericardial patch and translocated to a position lower in the left ventricular outflow tract. After suturing of the second row, central plication and commissural plication with autologous pericardium were added. After confirmation of the competency of the aortic cusp, implantation of the coronary arteries and ascending aorta replacement was completed. Video available at: https://www.jtcvs.org/article/S0022-5223(19)30469-6/fulltext.

advantages in QAV repair: (1) the ability to realign the commissures symmetrically and at an equal height and (2) narrowing of the annulus to establish a competent aortic valve, which has a greater coaptation height. The preoperative annuloventricular junction index was large relative to the restricted cusp because de Kerchove and colleagues $^{3}$ have recommended reimplantation technique whenever the annuloventricular junction is at least $28 \mathrm{~mm}$ (index, $13.3 \mathrm{~mm} / \mathrm{m}^{2}$ ). With regard to the surgical approach for tricuspidization, the angles of the 3 fashioned commissures should be considered in concert with the depth and height of the new leaflets relative to the annulus. In this case, annuloplasty with cusp elongation and translocation was effective to obtain good coaptation when the rudimentary cusp was obliterated. These concepts have already been applied in bicuspid valve repair. $^{4}$

The greatest concern associated with VSRR is the surgical risk. In experienced institutions, however, the reported in-hospital mortality is low $(1.2 \%) .^{5}$ VSRR may be a reasonable option for the younger patient population for whom avoiding of anticoagulation is preferred.

\section{CONCLUSIONS}

The surgical outcome of asymmetric QAV repair was satisfactory. Reconfiguration of QAV into a symmetric morphology may be a feasible option for younger patients.

\section{References}

1. Tsang MY, Abudiab MM, Ammash NM, Naqvi TZ, Edwards WD, Nkomo VT, et al. Quadricuspid aortic valve: characteristics, associated structural cardiovascular abnormalities, and clinical outcomes. Circulation. 2016;133:312-9.

2. Yamanaka K, Okada K, Okita Y. Aortic root replacement with a valve-sparing technique for quadricuspid aortic valve. Eur J Cardiothorac Surg. 2015;47:741-3.

3. de Kerchove L, Mastrobuoni S, Boodhwani M, Astarci P, Rubay J, Poncelet A, et al. The role of annular dimension and annuloplasty in tricuspid aortic valve repair. Eur J Cardiothorac Surg. 2016;49:428-37; discussion 437-8.

4. Gleason TG. Bicuspid aortic valve repair by complete conversion from "raphe'd" (type 1) to "symmetric" (type 0) morphology. J Thorac Cardiovasc Surg. 2014; 148:2862-8. e1-2.

5. David TE, David CM, Feindel CM, Manlhiot C. Reimplantation of the aortic valve at 20 years. J Thorac Cardiovasc Surg. 2017;153:232-8. 